\title{
Role of Trans-Arterial Embolization in Management of Bone Tumors
}

\author{
WALAA MAHMOUD, M.D.*; MOHAMMED A.A. ELHAWARY, M.D.*; AHMED G. SADEK, M.D.*; \\ MOHAMED A. BORG, M.D.* and MOHAMED F.M. MOSTAFA, M.D.*** \\ The Departments of Diagnostic and Interventional Radiology* and Orthopedic Surgery**, Faculty of Medicine, \\ Mansoura University, Mansoura, Egypt
}

\begin{abstract}
Background: Trans-arterial embolization (TAE) is a promising less aggressive modality in either primary treatment or adjuvant to surgical management of bone tumors. The main aim is to induce necrosis and decrease bleeding and therefore facilitate resection. Palliation of compression manifestation of inoperable bone neoplasm is another indication of TAE. Frequent tumors selected to this modality include vascular tumors (particularly metastases), aneurysmal bone cysts $(\mathrm{ABC})$, giant cell tumor (GCT), and osteosarcoma.
\end{abstract}

Aim of Study: Our aim is to assess the role of embolization in management of bone tumors.

Patients and Methods: The current study prospectively evaluated 33 patients ( 23 males and 10 females). Their age ranged from 9 to 69 years (mean age of 43.246 \pm 19.65 ). Extremities, hip, vertebrae, and skull were involved by variety of bony tumors. Sixteen patients were affected by primary osseous tumors, while 17 patients had metastases. A transarterial embolization was done in all patients as a preoperative procedure in 15 patients, definite treatmentof primary benign inaccessible tumors in 6 patients, prebiopsy embolization in 6 patients, and as a palliative treatment in 6 patients.

Results: Technical success was obtained in 30 out of 33 cases with percentage of $90.9 \%$. All benign and primary malignant bony tumors showed technical success while, $82.4 \%$ of metastatic lesions did.

Clinical success was achieved in $73.3 \%$ cases of first group, $83.3 \%$ of second group, $100 \%$ of third group and $66.7 \%$ of fourth group. Four patients $(12.1 \%)$ showed no clinical improvement with $9 \%$ lost follow-up.

Five out of 6 benign tumors showed clinical success $(83.3 \%)$ as the sixth case lost follow-up (16.7\%). Embolization of 9 of primary malignant lesions was clinically successful (90\%), whereas 12 out of 17 metastatic lesions were improved clinically (70.6\%), 3 cases showed no clinical success (17.6\%), and 2 cases were lost at follow-up (11.8\%).

Correspondence to: Dr. Walaa Mahmoud, The Department of Diagnostic and Interventional Radiology,

Faculty of Medicine, Mansoura University, Mansoura, Egypt
Conclusion: A high consideration should be given totransarterialembolization in the algorithmic treatment strategy of bone tumors as it is much safer and effective tool when diminution of bleeding and compression manifestations is to be specifically aimed.

Key Words: Transarterial - Embolization - Bone tumors Microcathetrs - PVA - Gelfoam.

\section{Introduction}

DIFFERENT lines of treatment of bone neoplasms are employed according to type of the tumor either primary or metastatic. Surgery is the conventional line of treatment with other additional therapies. Very large tumors, high vascularization, or proximity to important structures may lead to difficult and hazardous surgeries. Recently, transarterial embolization (TAE) is considered the most effectivepreoperative procedurewith subsequent rapid relief in pain and tumor shrinkagein the majority of boneneoplasms. It could be a definite treatment especially in benign tumors such as haemangioma and giant cell tumors [1,2]. Palliation of pain and neurological symptoms and, thereby improving life quality could be achieved successfully in those with irresectable bone neoplasia [3,4].

Promising results of TAE could be obtained whenthe bone tumor is hypervascular in nature such as giant cell tumors (GCT), aneurysmal bone cysts (ABC), haemangiomas, arterio-venous malformations, osteoblastoma, osteosarcomas and highly vascular metastases (renal cell or thyroid carcinomas) [5-8].

In this study, we aim to evaluate the efficacy of embolization as aninitial preoperative, curative or palliative treatment modality in bone tumors either primary or metastatic. 


\section{Patients and Methods}

Institutional Review Board (IRP) of our institution approved this prospective study and informed consents were obtained from all patients. The present study was conducted on cases referred to Department of Radiology, Mansoura University Hospitals from July 2017 till February 2020.The study enrolled 33 patients ( 23 males and $10 \mathrm{fe}-$ males) with vascular bone tumors. The participants ranged from 9 to 69 years (mean age of $43.246 \pm$ 19.65).

According to the purpose of the embolization the included patients were categorized into 4 groups; preoperative embolization $(n=15,45.5 \%)$, definite treatment $(n=6,18.2 \%)$, pre-biopsy embolization $(\mathrm{n}=6,18.2 \%)$, and palliative embolization $(n=6,18.2 \%)$.

Benigntumors were found in 6 cases $(18.2 \%$; aneurysmal bone cyst in 5 cases and vertebral hemangioma in one case). Primary malignant bone tumors were found in 10 cases $(30.3 \%$; osteosarcoma in 6 cases, plasmacytoma in 2 cases, chondrosarcoma and recurrent sacral sarcoma in one case each). Seventeen patients $(50.1 \%)$ were diagnosed with metastatic bony lesions (HCC in 6 cases, RCC in 4 cases, pancreatic and thyroid cancers in 2 cases for each, colonic, breast, and chondrosarcoma in one case for each). Preprocedural pathological diagnosis was obtained in all patients except in patients referred for prebiopsy embolization.

The most common encountered affected bone was humerus $(\mathrm{n}=8 ; 24.2 \%)$, followed by iliac bone $(n=5 ; 15.2 \%)$, and sacrum $(n=5 ; 15.2 \%)$. Other sites are illustrated in (Table 1).

Table (1): Demonstrating anatomical sites of bony lesions in included 33 cases.

\begin{tabular}{ll}
\hline Tumor site & Number $(\%)$ \\
\hline Scapula & $3(9.1 \%)$ \\
Humerus & $8(24.2 \%)$ \\
Femur & $3(9.1 \%)$ \\
Acetabulum & $2(6.1 \%)$ \\
Clavicle & $3(9.1 \%)$ \\
Iliac bone & $5(15.2 \%)$ \\
Pubic bone & $2(6.1 \%)$ \\
Tibia & $1(3 \%)$ \\
Skull & $1(3 \%)$ \\
Sacrum & $5(15.2 \%)$ \\
\hline
\end{tabular}

Pre-procedural laboratory investigations were done to guarantee safe embolization. CTA and/or MRA were done to assess the feeding vessels and mapping the treatment strategy.

\section{Technique:}

Embolization and pre-procedural angiography both were done using either (Phillips - AlluraXper FD20/20 X-ray system) or (Philips BV pulsera Carm W/9'ii/Flat panels-Vascular Package), under local anesthesia. Common femoral artery approach was used in all procedures. Initial flush arteriogram was performed to map out arterial anatomy. For spinal and pelvic tumors, an aortogram is performed initially; however, for peripheral tumors, an arteriogram of the main extremityartery was performed. When stable selective catheterization was acomplished, a microcatheterwas used to target the direct supplying arteries of the tumor.

Selective catheterization was achieved using either copra, angled catheter, rim, Mani or glide catheters, while coaxial microcatheterization was done in 29 patients $(87.9 \%)$ using Progreat (in 25 cases; $75.8 \%$ ), Renegade was used alone in 2 cases $(6.1 \%)$ and in conjugation with Marathon in one case, whereas Merit catheter was used in only one case.

Twenty eight embolizations were performed using single embolic material (gel-foam in 18 cases; $54.5 \%$ and polyvinyl alcohol in 10 cases; $30.3 \%$ ). In 4 cases we used a mixture of PVA and Gel-foam, while PVA with gel-foam and pushable coil were used in the remaining case.

Reaching the angiographic endpoint could be achieved by loss of blush in vascular bed of the tumor; however, anyreduction inantegradeblood flow could be considered a successful technical outcome (Fig. 1). It was performed before $24 \mathrm{~h}$ of surgery to avoidformation of collateral vesselsin the interval between the embolization and surgery.

Patients comprised in the pre-operative embolization group (45.5\%) were compared with additional randomly chosen group (no TAE was done) with no statistically different mean age, tumor size, vascularity, bleeding tendency measurementsand operating team. Technical success (regardingintra-operative blood loss) was evaluated in both groups. Peri-operative blood loss was quantified by measuring blood in thesuction machine, weighting the operative sponges during surgery, measuring irrigation fluid, and from the postoperative suction drainage.

In definitive treatment embolization group (18.2\%), serial follow-up radiological studies were done for monitoring devacularization degree, increased CT density (due to sclerosis) or debulking of the tumor as well as decreased threshold and frequency of pain. 

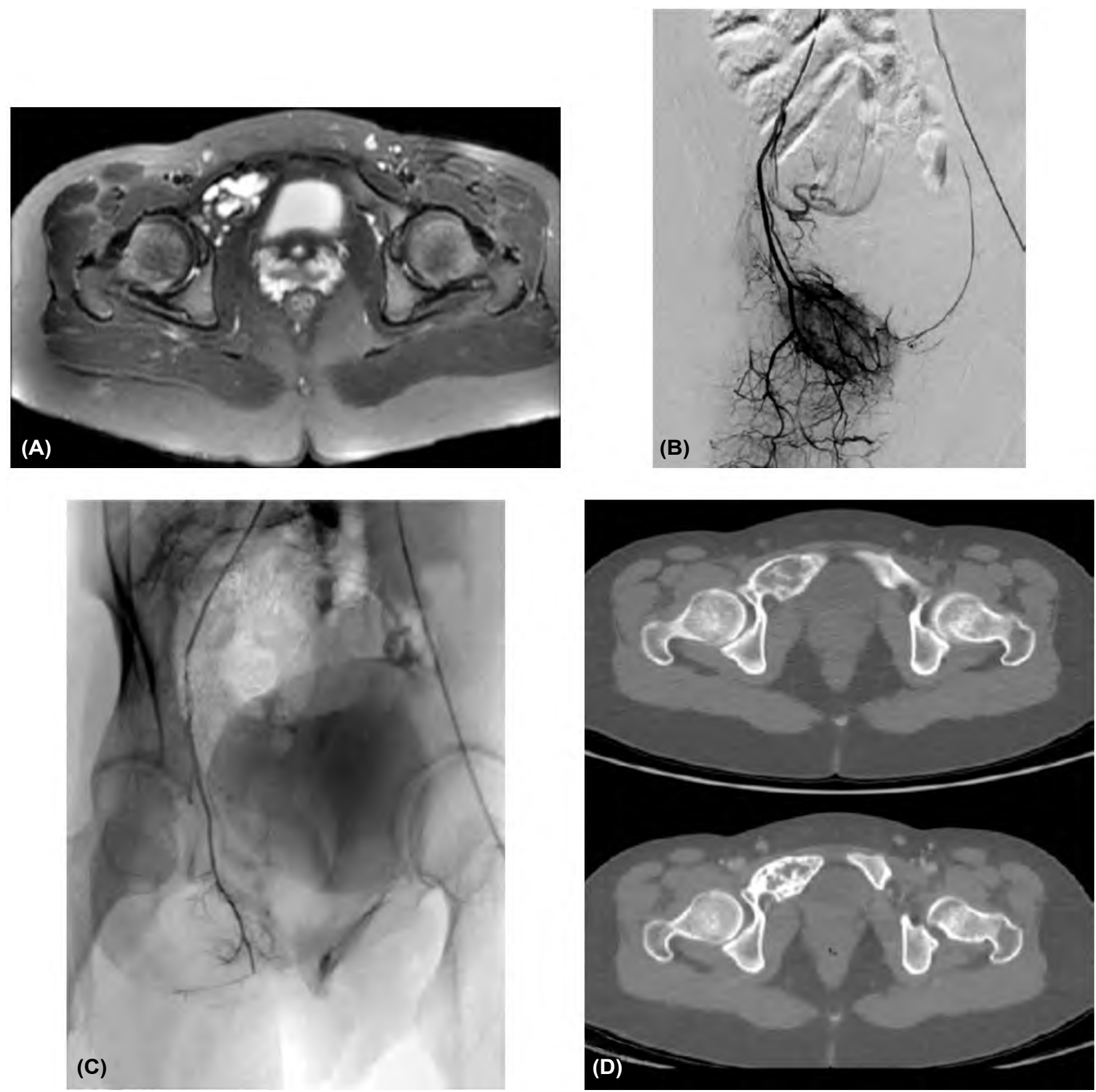

Fig. (1): Female patient 17 years old with right pubic ABC. (A): MRI pelvis revealed multilocular right pubic bone benign looking lesion with fluid fluid levels on T2 (ABC). (B): Pre-embolization significant Tumor blush. C: Post-embolization no blush. (D): 6 months interval CT revealed significant increased sclerosis and mild regression in size.

In pre-biopsy embolization group (18.2\%), intra-procedure blood loss monitoring was done. In palliative embolization group $(18.2 \%)$, clinical outcome was assessed by regression of either degree or frequency of hemorrhage, pain, and compression manifestations. Two doctors' reviews were obtained. If obviously opposingreviews; higher staff consultation was requested.

\section{Statistical analysis:}

The collected data was coded, processed and analyzed using SPSS program (version 21) for windows. The appropriate statistical tests wereused when needed. $p$-value less than 0.05 will be considered to be statistically significant.

\section{Results}

Technical success reflected immediate results of embolization and is typically evaluated with completion of angiography. It was monitored by evaluation if selective access of all feeders was done and subjective evaluation of devascularization rate. 
Technical success was obtained in 30 out of 33 cases with percentage of $90.9 \%$ (in $80 \%$ of pre resection embolization, in all patients of definitive treatment, pre-biopsy and palliative embolization groups (Table 2).

All benign and primary malignant bony tumors showed technical success while, $82.4 \%$ of metastatic lesions did.

The technical success of our procedure is dependent upon the superselective catherization of every single feeder and degree of devascularization which was obtained after TAE. Our subjective cut offpoint was $80 \%$. Only 4 cases had less than $80 \%$ with percentage about $12.1 \%$. In the other 29 cases, $80 \%$ devascularization or more wasobtained.

As regard the clinical success of embolization procedure in the first group (Table 3 ), the mean tumor diameter did not differ significantly between those patient who underwent TAE before surgery and the other group with no pre-operative embolization $(p=0.924)$. Although less intra-operative blood loss was observed after embolization $840 \mathrm{ml}$ vs. $1080 \mathrm{ml}$ without embolization but with no statistical significance $(p=0.133)$.

Regarding the 6 patients for whom TAE was performed for curativeintention, the number of embolization sessions ranged between 1-3 sessions. CT angiography was used for follow-up. The follow-up periodranged between 3 and 12 months. However, one case was lost during follow-up. Apart from that case, decreased vascularity and increaseddensity were detected in other lesions after intervention (83.3\%). Moreover, clinicalimprovement and decreased tumor size was also reported in that 5 cases.

Concerning the 6 patients who were referred for TAE as pre-biopsy tool, all cases showed no significant blood loss, smooth procedure and were discharged in same day without significant complication.

The remaining 6 cases who were referred for TAE as palliative treatment, clinical success was detected in all cases apart from two cases who were lost during follow-up (66.7\%). Clinical success was measured by symptom improvement and it was judged by two different observers.

Our procedure was accomplished without any significant complications in about 21 cases $(63.6 \%)$. But puncture site and local tumor pain were the main complications and they were noted in 7 cases $(21.2 \%)$. It was managed by simple analgesics in all cases. Broken catheter (copra) tips, dissection of the feeding branch, rupture of small parietal branch were noticed in single case for each.

Five out of 6 benign tumors showed clinical success $(83.3 \%)$ as the sixth case lost follow-up $(16.7 \%)$. Embolization of 9 (out of 10) primary malignant lesions was clinically successful (90\%), whereas 12 out of 17 metastatic lesions were improved clinically $(70.6 \%), 3$ cases showed no clinical success $(17.6 \%)$, and 2 cases were lost at follow-up (11.8\%). (Fig. 2).

Table (2): Technical success according to Trans-Arterial Embolization indication.

\begin{tabular}{|c|c|c|c|c|c|}
\hline & $\begin{array}{l}\text { Preoperative } \\
\qquad(\mathrm{n}=15)\end{array}$ & $\begin{array}{l}\text { Definitive } \\
\quad(n=6)\end{array}$ & $\begin{array}{c}\text { Pre- } \\
\text { biopsy } \\
(\mathrm{n}=6)\end{array}$ & $\begin{array}{c}\text { Palliative } \\
\quad(n=6)\end{array}$ & $\begin{array}{c}\text { Total } \\
(\mathrm{n}=33)\end{array}$ \\
\hline No & $3(20 \%)$ & $0(0 \%) \mathrm{O}$ & $(0 \%)$ & $(0 \%)$ & 3 \\
\hline Yes & $12(80 \%) 6$ & $5(100 \%) 6$ & $(100 \%)$ & $6(100 \%)$ & $30(80 \%)$ \\
\hline
\end{tabular}

Table (3): Comparison between operative cases with and without preoperative embolization.

\begin{tabular}{|c|c|c|c|}
\hline Parameter & $\begin{array}{c}\text { Operated cases } \\
\text { without } \\
\text { pre-operative } \\
\text { TAE }\end{array}$ & $\begin{array}{c}\text { Operated cases } \\
\text { with } \\
\text { pre-operative } \\
\text { TAE }\end{array}$ & $t / \mathrm{Z}$ \\
\hline Max diameter & $10.2 \pm 2.8$ & $10.1 \pm 2.9$ & $t=0.096$ \\
\hline $\begin{array}{l}\text { Intra-operative } \\
\text { blood loss }\end{array}$ & $1080 \pm 289$ & $840 \pm 528$ & $t=1.545$ \\
\hline $\begin{array}{l}\text { Units of blood } \\
\text { transfusion } \\
\text { needed }\end{array}$ & $2(1-2)$ & $1(0-2)$ & $Z=-1.493$ \\
\hline
\end{tabular}

Bar Chart

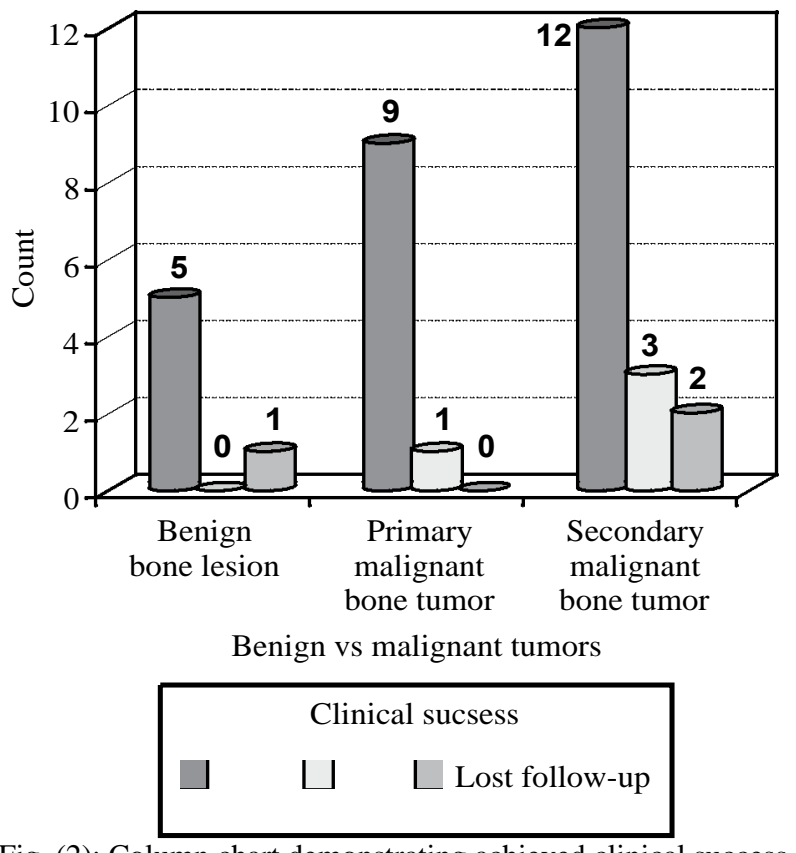

Fig. (2): Column chart demonstrating achieved clinical success according to tumor classification. 

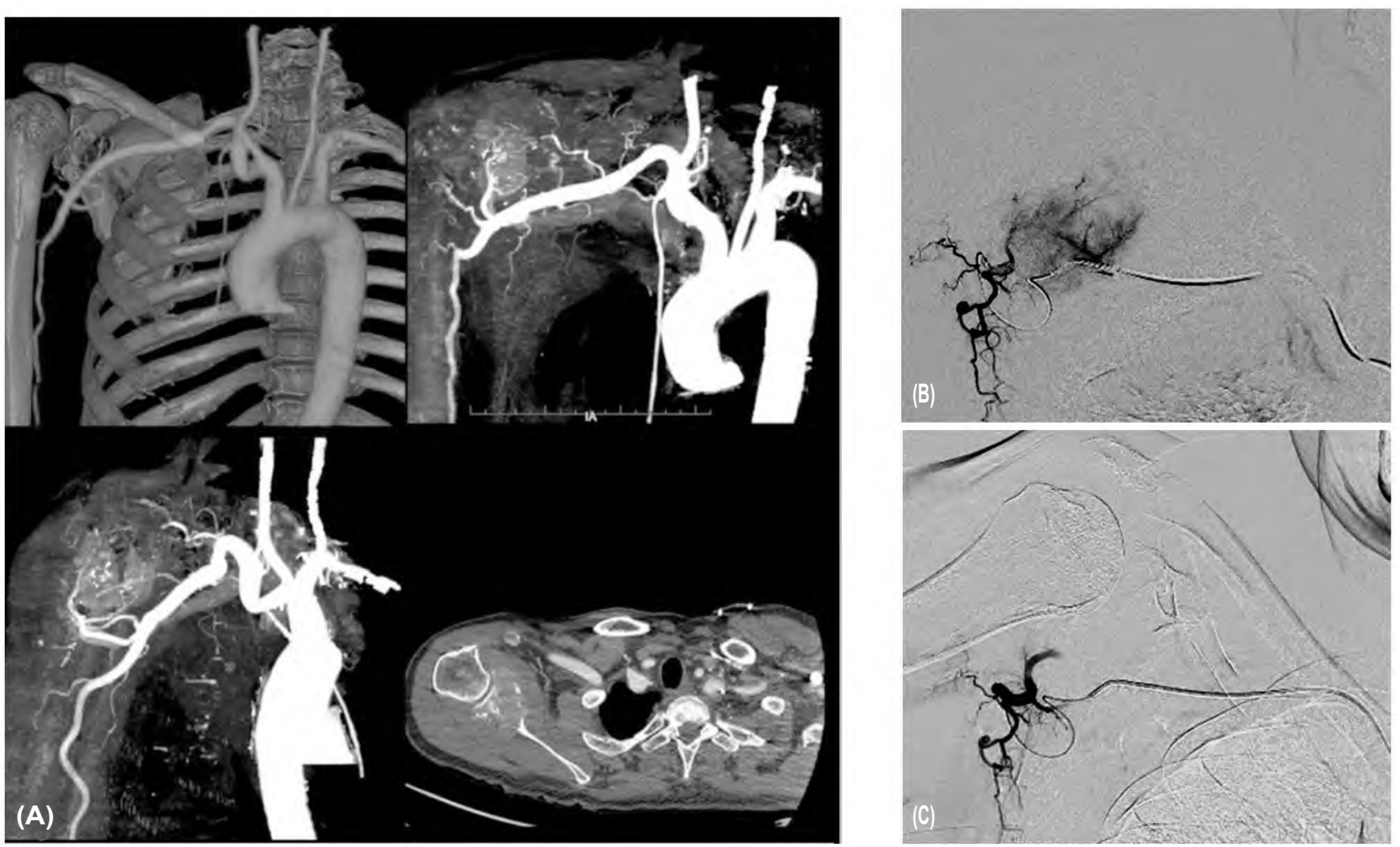

Fig. (3): Male patient 62 years old with a well-defined destructive bony lesion seen at the right glenoid with extensive large extra-osseous soft tissue component. (A): CT angiography of the right upper limb revealed the previously described pathologically proven plasmacytoma. (B): Pre-embolization run (DSA) after super-selective catherization of the main feeding artery using merit microcatheter revealed significant tumor blush. (C): Post-embolization run (DSA) after super-selective catherization of the main feeding artery using merit microcatheter revealed no significant tumor blush.
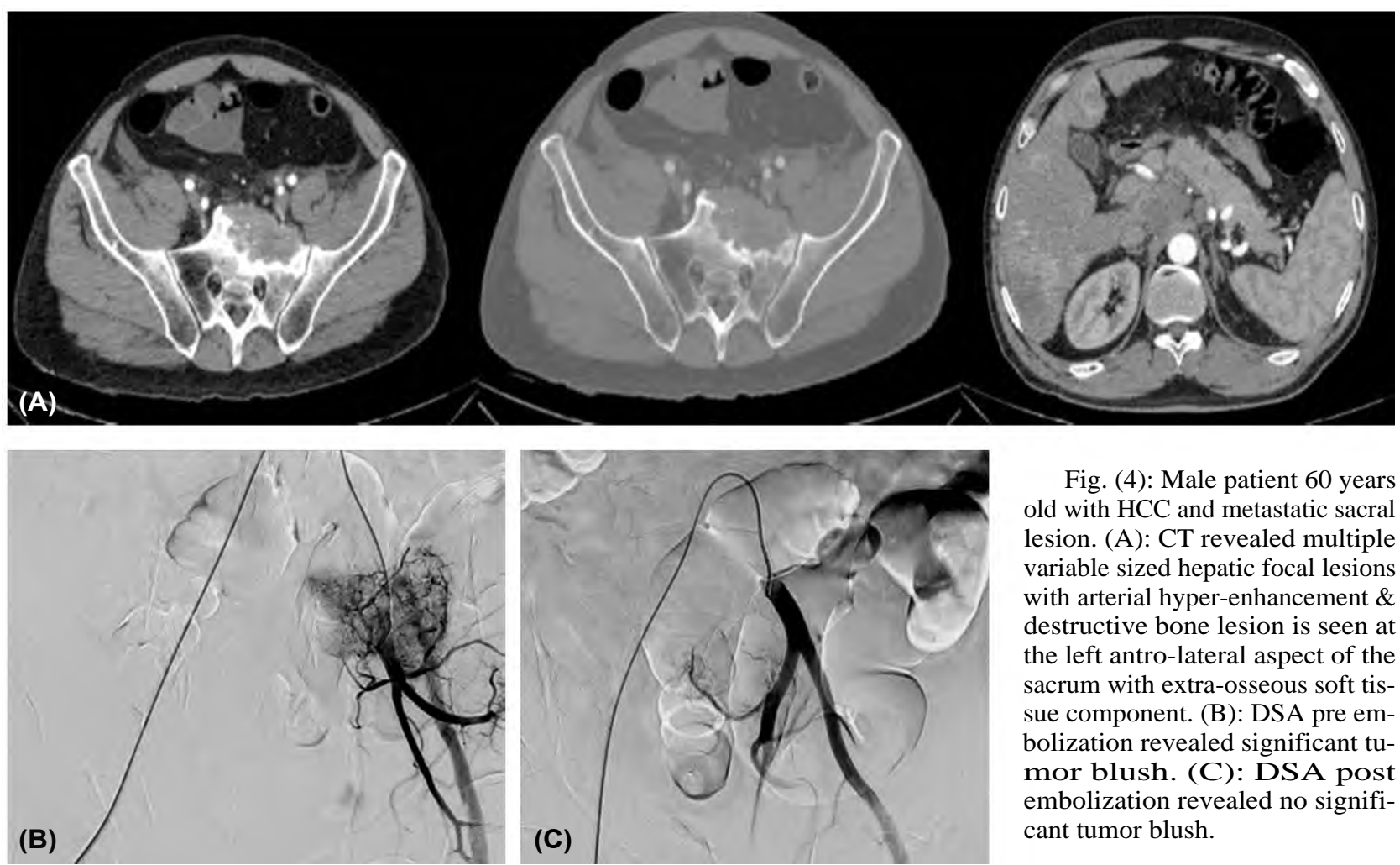

Fig. (4): Male patient 60 years old with HCC and metastatic sacral lesion. (A): CT revealed multiple variable sized hepatic focal lesions with arterial hyper-enhancement \& destructive bone lesion is seen at the left antro-lateral aspect of the sacrum with extra-osseous soft tissue component. (B): DSA pre embolization revealed significant tumor blush. (C): DSA post embolization revealed no significant tumor blush. 


\section{Discussion}

Therapeutic embolization could be carried out with different intentions. It may be utilized as an operative adjuvant aiming to diminish thepotential hazard of hemorrhage, better delineation of tumor margins and thereby, simplification of surgery especially in highly vascularised lesions. Also, it could be employed as a relatively less aggressive palliative procedure in a patient with poor condition or when surgical intervention is hazardous. Moreover, pain palliation, relief of fever and hypercalcemia are considered valuable indications of TAE in the setting of bone tumor management. Embolization may enhance response of tumor cells to radiation or chemotherapy $[\mathbf{7 , 9 , 1 0 ]}$.

Embolization aims to keep up ischemia and necrosis within the centerof the tumor, by occluding small distal feeders inside the tumor. Thus, atumor will shrink, borders between the tumor and the surrounding tissue will become distinct, improving ability of the surgeon to control bleeding leading to easier surgical excision and manipulation [11].

Vast majority of the similar previous studies suggested that TAE was performed under local anaesthesia as done in our study.

In our study, only 5 cases had $>/=1000 \mathrm{ml}$ intraoperative blood loss (metastatic HCC, breast carcinoma, RCC, osteosarcoma and recurrent sacral sarcoma) with devascularization less than $80 \%$ in four of them. The degree of devascularization which was obtained after TAE was $80 \%$ or more in 29 cases.

In the same context, Sun and Lang's [12] reported in their experiences with 16 patients that bleeding reduces significantly in lesions of $>70 \%$ devasclarization degree on follow-up angiographies.

Wirbel et al. [13] agreed that hypervascular bony metastatic lesions represent a surgical challenge. In theirstudy of 32 patients with a preoperative TAE, there was a significant difference in blood loss and transfusion requirements compared with non embolized controls. The operation time was shorter yet with no statistical significance. There were no attributable neurological deficits.

In another study, Chu et al. [14] used chemoembolic combination and found that application of transarterial chemoembolization (TACE) appears to enhance tumorcell necrosis and lead to decrease incidence of local recurrence.

In this work, all cases were operated 1 day after embolization apartfrom one case operated 3 days after the embolization session. Barton [15] reported thatan interval of 3 or more days between embolization and surgery had raised the risk of blood loss in those patients because of rapid revascularization of tumors.

In the current study, embolization was employed as a definitive treatment of 6 benign tumors ( 5 $\mathrm{ABC}$ and one vertebral haemangioma). Three cases of $\mathrm{ABCs}$ were embolized twice, one case threetimes and the last one was embolized only one time. Technical success was achieved in all cases (100\%), while clinical success was experienced in 5 cases as one caselost follow-up. CTA revealed decreased vascularity, significant increased density of the lesion with mild regression in size was noted in 4 cases.

Guzey et al. [16] reported that embolization, in addition to radiation therapy and cryotherapy, had been used for management of recurrent or inaccessible aneurysmal bone cysteither as a primary or a preoperative procedure insteade of surgical resection alone which used to be the treatments of choice but with increased risk of local recurrence.

In similar studies, Börüban et al., Yildirim et al., and Rossi et al. [17-19] found that embolization of $\mathrm{ABC}$, either alone or followed by resection, and curettage improved resolution of lesions with no recurrence.

Lin et al. [20] had similar results in their study done for 18 GCT with $50 \%$ of patients showed durable response and $31 \%$ showed local recurrence at 10 years and $43 \%$ at 15 years. Börüban et al. [17] used TAE in two cases of haemangioma with less satisfactory results.

A preoperative biopsyprecipitated massive hemorrhage in vascular bone tumors which could be managed with TAE [21]. This was in agreement with our 6 cases referred for a pre-biopsy embolization who showed devasculaization rate more than $80 \%$. The procedure was smooth with insignificant blood loss.

In this study; sex cases was embolized as a palliative treatment. They were refereed for intolerablepain (5 cases), limited movement (5 cases), and significant increased lesional growth rate with intra-tumoral hemorrhage ( 2 cases). One of them lost follow-up while other cases show subjective clinical improvement.

Targeted occlusion of the feeding vessels after embolization will reduce the volume of a tumor; thus, compression on the elevated periosteum will 
be revoked and contributes to painal leviation. The pain-free period may be variable and re-embolization may be needed in some cases. In the literature, reported pain-free periods are between 2 and 8 months $[\mathbf{2 , 9 , 2 2 , 2 3 , 2 4 ]}$.

In the current study, TAE procedure was completed with usage of coaxial system in 29 cases. The most used microcatheter was Progreat, which was used in 25 cases $(75.8 \%)$.

Usage of microcathetersis considerably advantageous as they providetarget delivery of the embolic agent further from the parent vessel to smaller feeding branches and therefore doubt less cut back the possibility of non-target embolization (Fig. 3) $[9,24]$.

More recently, the development of upgraded coaxial microcatheters, guidewires, and digital angiographic equipment have enabled moreperipheral superselective catheterization of distal vessels, allowing moreselective vascular interventions [2528].

In our study, gel foam was the mostcommon used embolic material (18 cases-54.5\%), followed by PVA (10 cases-30.3\%).

The chosen embolic material should suits the catheter size and diameter of targeted vessels. Familiarity with the unique pharmaceutical properties of each embolic agent, desired outcome of embolization procedures, flow characteristic and expected complication should be considered [7,29].

There are few published comparative studiesabout technical results of different embolic material (particles, gel-foam, liquids, coils). Liquid embolics (absolute alcohol, N-butyl cyanoacrylate, ethylene vinyl alcohol) may provide moretumor necrosis than particules (e.g. PVA). This is to be advantageous where definite treatment is desired but carries an increased potential accidental non-target embolizationand necrosis and thus require more experience $[18,30,31,32]$.

In this study, significant numbers of bony tumors managed with TAE was in the appendicular skeleton $(n=26,79 \%)$ with metastases were the commonest pathological entity $(n=17)$. In contrast, to othersimilar studies, spinal column was the most common site, especially for metastases $[33,34]$. However, results of Jha et al. [7], Shimohira et al. [24] and Suster et al. [35] agreed with ours. In the study of Geraets et al. [36], RCC metastases were the most frequent lesion on the contrary of our study where HCC metastases were the most fre- quent ( $\mathrm{n}=6,35 \%$ of metastatic lesions) as demonstrated in Fig. (4) [36].

The findings of this study have to be seen in light of some limitations. The first isthe short term follow-up of the patients. The long term monitoring of the clinical outcome of the procedure (by serial $\mathrm{X}$-ray and CT) is crucial particularly if embolization is used as a curative method of treatment. The second is the relative small patients group. Larger number of patients isrequired for confirmation of thereliability and efficacy of the technique.

\section{References}

1- GUPTA P. and GAMANAGATTI S.: Preoperative transarterialembolisation in bone tumors. World J. Radiol., 4 (5): 186-92, 2012.

2- ABD EL-KHALEK, AHMED M., et al.: "Outcomes of embolization of bone tumors in the pelvic and shoulder girdles: Initial experience. The Egyptian Journal of Radiology and Nuclear Medicine, 49.1: 85-91, 2018.

3- MARCIEL, ANN MARIE, BRYAN L. VAN ZANDT and AARON J. BAXTER: Transcatheter arterial embolization for the palliation of painful bone lesions. Techniques in Vascular and Interventional Radiology, 14.3: 141-149, 2011.

4- MAVROGENIS, ANDREAS F., et al.: Palliative embolization for osteosarcoma. European Journal of Orthopaedic Surgery \& Traumatology, 24.8: 1351-1356, 2014.

5- SIMPSON A.H., PORTER A., DAVIS A., GRIFFIN A., McLEOD R.S. and BELL R.S.: Cephalad sacral resection with a combined extended ilioinguinal and posterior approach. J. Bone Joint Surg. Am., 77: 405-411, 1995.

6- CHU J.P., CHEN W., LI J.P., ZHUANG W.Q., HUANG Y.H., HUANG Z.M. and YANG J.Y.: Clinicopathologic features and results of transcatheter arterial chemoembolization for osteosarcoma.Cardiovasc. Intervent Radiol., 30: 201-206, 2007.

7- JHA R., SHARMA R., RASTOGI S., KHAN S.A., JAYASWAL A. and GAMANAGATTI S.: Preoperative embolization of primary bone tumors: A case control study. World Journal of Radiology, 8 (4): 378, 2016.

8- MAVROGENIS, ANDREAS F., et al.: "Embolization of bone tumors". Orthopedics, 34.4: 303-310, 2011.

9- OWEN R.J.: Embolization of musculoskeletal bone tumors. Semin Intervent Radiol., 27 (2): 111-23, 2010.

10- ROSSI G., MAVROGENIS A., RIMONDI E., CICCARESE F., TRANFAGLIA C., ANGELELLI B. and RUGGIERI P.: Selective arterial embolisation for bone tumours: Experience of 454 cases. La radiologiamedica, 116 (5): 793-808, 2011.

11- GUZMAN R., DUBACH-SCHWIZER S., HEINI P., LOVBLAD K.-O., KALBERMATTEN D., SCHROTH G. and REMONDA L.: Preoperative transarterial embolization of vertebral metastases. European Spine Journal, 14 (3): 263-268, 2005.

12- SUN S. and LANG E.V.: Bone metastases from renal cell carcinoma: Preoperative embolization. Journal of Vascular and Interventional Radiology, 9 (2): 263-269, 1998. 
13- WIRBEL R.J., ROTH R., SCHULTE M., KRAMANN B. and MUTSCHLER W.: Preoperative embolization in spinal and pelvic metastases. Journal of Orthopaedic Science, 10 (3): 253-257, 2005.

14- CHU J.-P., CHEN W., LI J.-P., ZHUANG W.-Q., HUANG Y.-H., HUANG Z.-M. and YANG J.-Y.: Clinicopathologic features and results of transcatheter arterial chemoembolization for osteosarcoma. Cardiovascular and interventional radiology, 30 (2): 201-206, 2007.

15- BARTON P.P., WANECK R.E., KARNEL F.J., RITSCHL P., KRAMER J. and LECHNER G.L.: Embolization of bone metastases. Journal of Vascular and Interventional Radiology, 7 (1): 81-88, 1996.

16- GUZEY F.K., EMEL E., AYCAN A., BAS N.S., SEYITHANOGLU M.H., OZKAN N. and KARABULUT C.: Pediatric vertebral and spinal epidural tumors: A retrospective review of twelve cases. Pediatric Neurosurgery, 44 (1): 14-21, 2008.

17- BÖRÜBAN S., SANCAK T., YILDIZ Y. and SAGLIK Y.: Embolization of benign and malignant bone and soft tissue tumors of the extremities. Diagnostic and Interventional Radiology, 13 (3): 164, 2007.

18- YILDIRIM E., ERSÖZLÜ S., KIRBAS I., ÖZGÜR A.F., AKKAYA T. and KARADELI E.: Treatment of pelvic aneurysmal bone cysts in two children: Selective arterial embolization as an adjunct to curettage and bone grafting. Diagnostic and Interventional Radiology, 13 (1): 49, 2007.

19- ROSSI G., RIMONDI E., BARTALENA T., GERARDI A., ALBERGHINI M., STAALS E.L. and MERCURI M.: Selective arterial embolization of 36 aneurysmal bone cysts of the skeleton with N-2-butyl cyanoacrylate. Skeletal Radiology, 39 (2): 161, 2010.

20- LIN P.P., GUZEL V.B., MOURA M.F., WALLACE S., BENJAMIN R.S., WEBER K.L. and YASKO A.W.: Longterm follow-up of patients with giant cell tumor of the sacrum treated with selective arterial embolization. Cancer, 95 (6): 1317-1325, 2002.

21- HANSCH A., NEUMANN R., PFEIL A., MARINTCHEV I., PFLEIDERER S., GAJDA M. and KAISER W. A.: Embolization of an unusual metastatic site of hepatocellular carcinoma in the humerus. World Journal of Gastroenterology: WJG, 15 (18): 2280, 2009.

22- TAM, ALDA and AHRAR, KAMRAN: Palliative interventions for pain in cancer patients. In: Seminars in Interventional Radiology. Thieme Medical Publishers, 419, 2007.

23- VAN TOL K., HEW J., JAGER P., VERMEY A., DULLAART R. and LINKS T.: Embolization in combination with radioiodine therapy for bone metastases from differentiated thyroid carcinoma. Clinical Endocrinology, 52 (5): 653-659, 2000.

24- SHIMOHIRA M., NAGAI K., HASHIZUME T., NAKAGAWA M., OZAWA Y., SAKURAI K. and SHIBAMOTO Y.: Preoperative transarterial embolization using gelatin sponge for hypervascular bone and soft tissue tumors in the pelvis or extremities. Actaradiologica, 57 (4): 457$462,2016$.

25- SHIMOHIRA M., OGINO H., KAWAI T., KUSHITA A., WATANABE M., KAWAGUCHI T. and SHIBAMOTO Y.: Use of the triaxialmicrocatheter method in superselective transcatheter arterial chemoembolisation for hepatocellular carcinoma. The British Journal of Radiology, 84 (998): 184-187, 2011.

26- TROJANOWSKI P., JARGIEL L O T., TROJANOWSKA A. and KLATKA J.: Epistaxis in patients with hereditary hemorrhagic telangiectasia treated with selective arterial embolization. Actaradiologica, 52 (8): 846-849, 2011.

27- SHIMOHIRA M., OGINO H., KAWAI T., SAKURAI K., NAKAGAWA M. and SHIBAMOTO Y.: Clinical usefulness of the triaxial system in superselectivetranscatheter arterial chemoembolization for hepatocellular carcinoma. Actaradiologica, 53 (8): 857-861, 2012.

28- ZUO, MENGXUAN, et al.: Superselectivetranscatheter arterial embolization to control renal hemorrhage after partial nephrectomy for renal tumors: A report of 9 cases and a literature review. Journal of Interventional Medicine, 2.3: 134-138, 2019.

29- AHMAD, SAIMA: Endovascular embolization of highly vascular head and neck tumors. Interdisciplinary Neurosurgery, 19: 100386, 2020.

30- BASILE A., RAND T., LOMOSCHITZ F., TOMA C., LUPATTELLI T., KETTENBACH J. and LAMMER J.: Trisacryl gelatin microspheres versus polyvinyl alcohol particles in the preoperative embolization of bone neoplasms. Cardiovascular and Interventional Radiology, 27 (5): 495-502, 2004.

31- MUNK P.L. and LEGIEHN G.M.: Musculoskeletal interventional radiology: Applications to oncology. SeminRoentgenol, 42 (3): 164-74, 2007.

32- LORD J., BRITTON H., SPAIN S.G., et al.: Advancements in the development on new liquid embolic agents for use in therapeutic embolisation. J. Mater Chem. B., 8 (36): 8207-8218, 2020.

33- KOIKE Y., TAKIZAWA K., OGAWA Y., MUTO A., YOSHIMATSU M., YAGIHASHI K. and NAKAJIMA Y.: Transcatheter arterial chemoembolization (TACE) or embolization (TAE) for symptomatic bone metastases as a palliative treatment. Cardiovasc. Intervent Radiol., 34: 793-801, 2011.

34- THIEX R., HARRIS M.B., SIDES C., BONO C.M. and FRERICHS K.U.: The role of preoperative transarterial embolization in spinal tumors. A large single-center experience. Spine J., 13: 141-149, 2013.

35- SUSTER, DAVID, HUNG, YIN PUN and NIELSEN G. PETUR: Differential Diagnosis of Cartilaginous Lesions of Bone. Archives of Pathology \& Laboratory Medicine, 144.1: 71-82, 2020.

36- GERAETS S.E.W., BOS P.K., van der STOK J.: Preoperative embolization in surgical treatment of long bone metastasis: A systematic literature review. EFORT Open Rev., 5 (1): 17- 25, 2020. 


\section{دور الانصمام عن طريق الشرايين فى علاج أورام العظام}

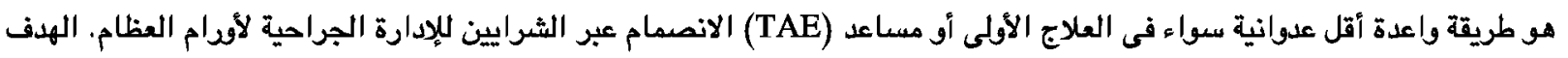

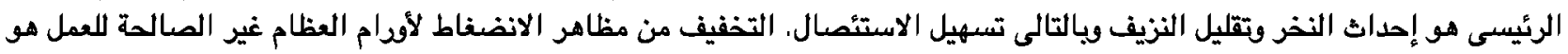

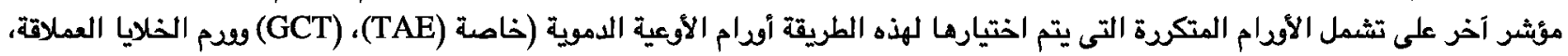

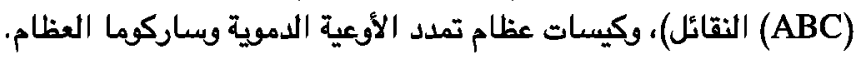

الهدف من العمل: قد أجريت الدراسة الحالية للكثف عن فعالية الانصمام قبل الجراحة، والعلاج ب هـ ا و تفيف الآلام من العظام الحميدة

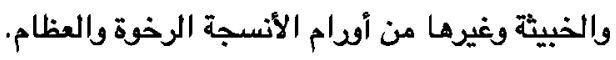

كثفت هذه الدراسة النتائج التالية:

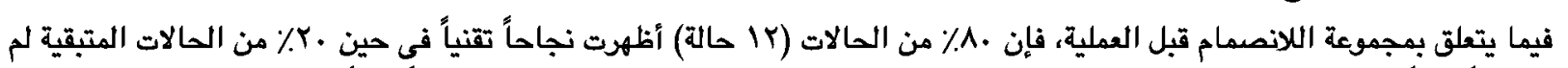

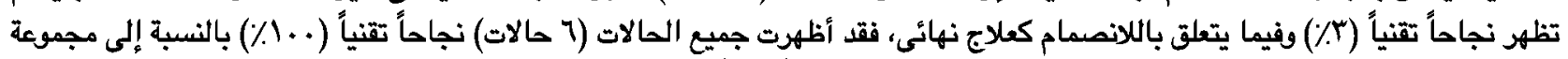

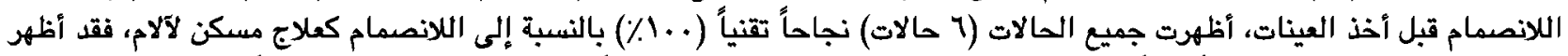

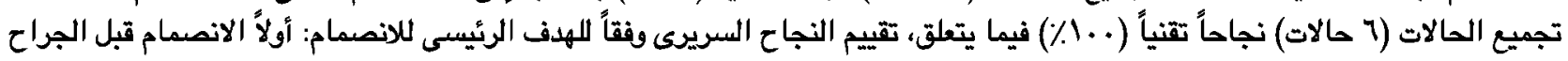

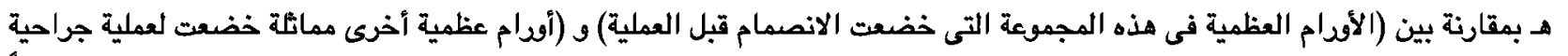

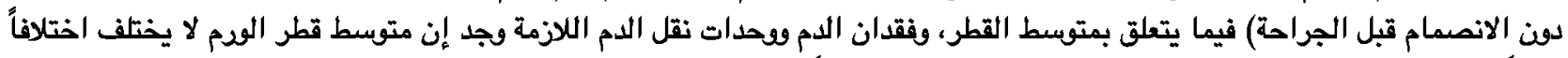

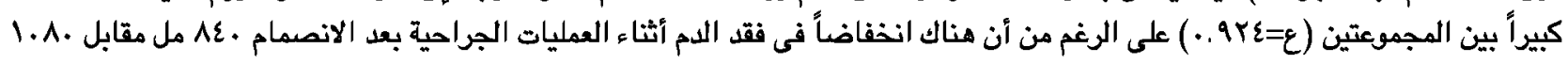

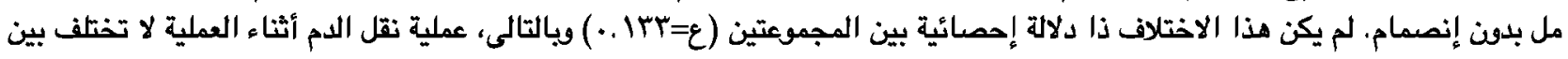

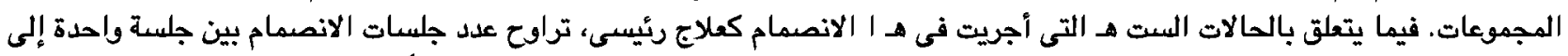

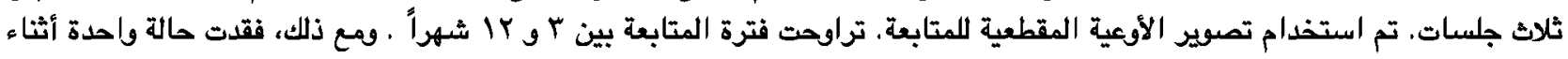

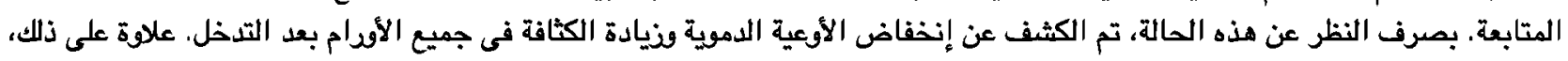

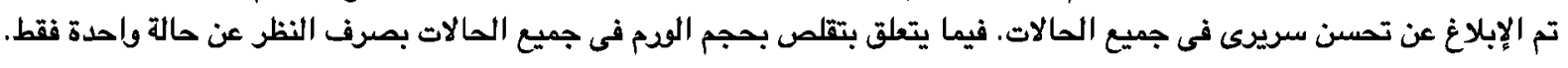

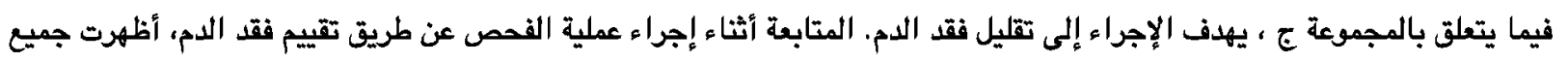

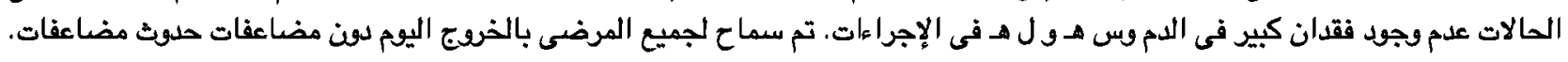

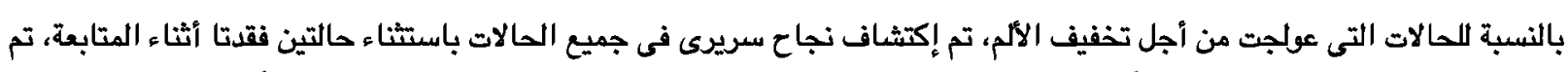

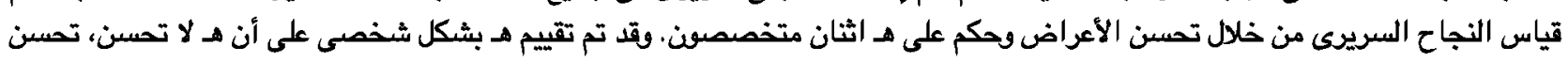
جزئى أو كامل.

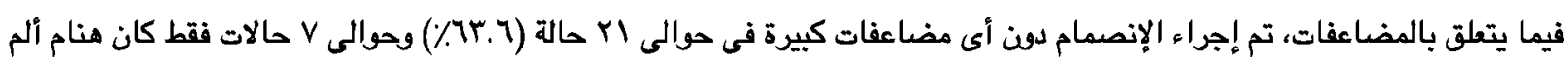

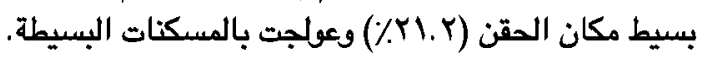

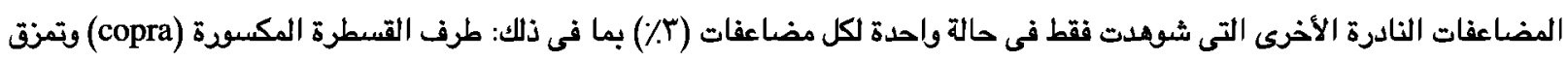

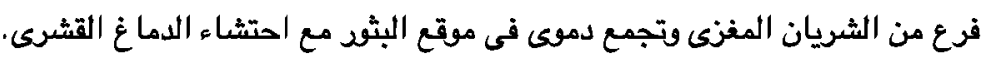
فيما يتعلق بالنجاح التقنى فى الأودام الحميدة والخبيثة: تم الحصل على نجاح الفنى فى •r حالة (9 .9\%) ولم يتم الحصول على هـ فى r حالات فقط (1. (9)). بخصوص المجموعات المرضية:

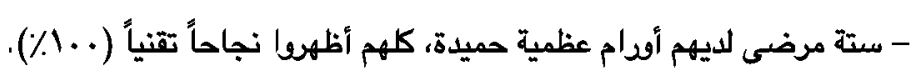

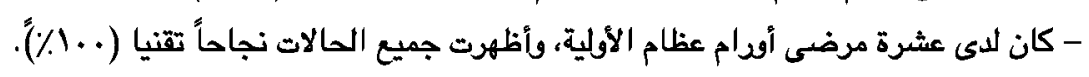

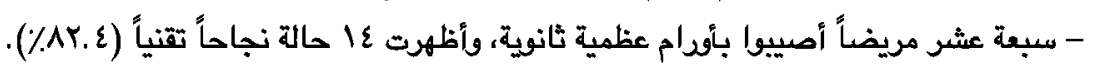

